\title{
Chloroform extract of Citrus unshiu Markovich peel induces apoptosis and inhibits stemness in HeLa human cervical cancer cells
}

\author{
YE SEUL CHOI $^{1,2^{*}}$, JANG MI HAN ${ }^{1,2^{*}}$, YUE JAI KANG ${ }^{3,4}$ and HYE JIN JUNG ${ }^{1,2,4}$ \\ Departments of ${ }^{1}$ Life Science and Biochemical Engineering, ${ }^{2}$ Pharmaceutical Engineering and Biotechnology, and \\ ${ }^{3}$ Aquatic Life and Medical Sciences, Sun Moon University; ${ }^{4}$ Genome-based BioIT Convergence Institute, \\ Asan, South Chungcheong 31460, Republic of Korea
}

Received April 3, 2020; Accepted November 11, 2020

DOI: $10.3892 / \mathrm{mmr} .2020 .11727$

\begin{abstract}
Cervical cancer is the second most common cancer among women worldwide. However, chemotherapies for this cancer often cause many side effects and chemoresistance. Citrus unshiu Markovich peel (CECU) has been used as a traditional medicine for the treatment of various diseases in East Asia. Recently, the anticancer activities and mechanisms of action of CECU extract have been reported in a number of different cancer cell types, but no study has evaluated the therapeutic effect of this natural product on cervical cancer cells. In the current study, the anticancer activity and the underlying molecular mechanism of the chloroform extract of CECU was investigated on HeLa human cervical cancer cells. The results showed that CECU effectively inhibited the proliferation and migration of HeLa cells. Treatment of cells with CECU led to cell cycle arrest at the G2/M phase and activation of extrinsic and intrinsic apoptotic pathways. Furthermore, the proliferation inhibitory effect of CECU was due to the inactivation of AKT and ERK signaling, upregulation of p53 and p21, and downregulation of cyclin B1 and cyclin D1, but not reactive oxygen species (ROS) generation. Furthermore, CECU inhibited the stem-like features of HeLa cells by downregulating key cancer stemness biomarkers. Therefore, CECU may be
\end{abstract}

Correspondence to: Professor Hye Jin Jung, Department of Pharmaceutical Engineering and Biotechnology, Sun Moon University, 70 Sunmoon-ro 221, Tangjeong-myeon, Asan, South Chungcheong 31460, Republic of Korea

E-mail:poka96@sunmoon.ac.kr

Professor Yue Jai Kang, Department of Aquatic Life and Medical Sciences, Sun Moon University, 70 Sunmoon-ro 221, Tangjeong-myeon, Asan, South Chungcheong 31460, Republic of Korea

E-mail:kyj5088@hanmail.net

*Contributed equally

Key words: cervical cancer, Citrus unshiu Markovich peel, apoptosis, cancer stem cells an effective complementary and alternative medicine for the prevention and treatment of cervical cancer.

\section{Introduction}

Cervical cancer is the second most common cancer among women worldwide. High-risk human papillomavirus (HPV) 16 and HPV 18 cause over $70 \%$ of cervical cancers (1). These cancers can be prevented with vaccines and, if diagnosed early, are highly curable. However, the outcome of patients with advanced cervical cancers remains poor due to recurrence, metastasis, and resistance to radiation and chemotherapy (2). Therefore, the discovery of promising anticancer agents for the prevention and treatment of cervical cancer is necessary.

Cancer cells can proliferate abnormally by avoiding apoptosis and cell cycle arrest $(3,4)$. Infection with HPV leads to the expression of oncogenes E6 and E7. E6 binds to p53 and disrupts its function through degradation, resulting in resistance to apoptosis. E7 inhibits another tumor suppressor, retinoblastoma 1 (RB1), thereby releasing E2F transcription factors that induce the expression of cell cycle regulators that stimulate cell proliferation $(5,6)$. Accordingly, recovery of apoptosis and cell cycle arrest are important strategies for the treatment of cervical cancer.

It has been recently reported that the recurrence and radio/chemotherapy resistance of cervical cancer are due to the presence of cancer stem cells (CSCs) $(7,8)$. CSCs cause genetic heterogeneity in cervical carcinoma, thereby lowering the effects of anticancer therapies and promoting metastasis to other tissues $(9,10)$. Several potential markers of cervical CSCs have been identified such as Sox2, ALDH1A1, CD133, integrin- $\alpha 6$, Nanog and Oct4 (11). They upregulate cancer stem-like features including self-renewal, tumorigenicity, and radio/chemo-resistance. For this reason, targeting CSCs can contribute to a better therapeutic outcome for cervical cancer.

Natural products have been used as medicine since ancient times and are often found to have several advantages in vivo, such as higher solubility and metabolic stability $(12,13)$. Moreover, natural components isolated from plants and with known biological activities have been developed as therapeutic agents for various human diseases. For example, the first 
microtubule stabilizing agent that was isolated from the bark of the tree Taxus brevifolia, paclitaxel has been used in the treatment of many types of solid tumors including breast and ovarian cancers (14). Besides, metformin that is widely used as the first-line medication for the treatment of type 2 diabetes was originally found in the plant Galega officinalis, known as French lilac (15). Citrus fruits are known to contain a variety of flavonoids, including hesperidin and naringenin, as their main ingredients (16). Citrus unshiu Markovich peel (CECU) has been used as a traditional medicine in China and Korea. It possesses antioxidant, anti-allergic, and anti-inflammatory effects, as well as cancer cell apoptotic and metastasis inhibitory activities (17-21). The ethanol extract of CECU has been shown to induce apoptosis of bladder cancer cells by inactivating the PI3K/AKT pathway (19). Water extract of the natural product showed anticancer effects against breast cancer cells through AMPK activation and ROS-mediated apoptosis $(20,21)$. However, there have been no studies on the effects of CECU extracts on cervical cancer cells. Moreover, previous studies have focused on investigating the anticancer effects of ethanol and water extracts of CECU (19-21). To further identify its anticancer activity, we obtained a non-aqueous fraction that is expected to contain non-polar substances of CECU. In this study, we investigated the anticancer activity and the molecular mechanisms involved in apoptosis-inducing and cancer stemness-inhibiting effects of the chloroform extract of CECU in HeLa human cervical carcinoma cells.

\section{Materials and methods}

Reagents and antibodies. Dulbecco's modified Eagle's medium (DMEM) was obtained from Corning Cellgro. Fetal bovine serum (FBS), DMEM/nutrient mixture F-12 (F12), B-27 serum-free supplement, L-glutamine, epidermal growth factor (EGF), basic fibroblast growth factor (bFGF), and penicillin/streptomycin were purchased from Gibco; Thermo Fisher Scientific, Inc. Heparin, 3-[4,5-dimethylthiazol-2-yl]2,5-diphenyl tetrazolium bromide (MTT), hesperidin, hesperetin, gallic acid, and crystal violet were purchased from Sigma-Aldrich; Merck KGaA. Penicillin-s treptomycin-amphotericin B was obtained from Lonza, Inc. Antibodies against p53 (53 kDa; cat. no. 2524), phospho-AKT (Ser473, 60 kDa; cat. no. 4060), AKT (60 kDa; cat. no. 9272), phospho-ERK1/2 (Thr202/Tyr204, 42,44 kDa; cat. no. 9101), ERK1/2 (42,44 kDa; cat. no. 9102), Bcl-2 (28 kDa; cat. no. 2872), Bcl-XL (30 kDa; cat. no. 2764), Bax (20 kDa; cat. no. 2772), cleaved caspase-3 (17,19 kDa; cat. no. 9661), cleaved caspase-9 (37 kDa; cat. no. 9501), cleaved caspase-8 (10 kDa; cat. no. 9748), PARP (89,116 kDa; cat. no. 9542), DR5 (40,48 kDa; cat. no. 8074), Fas (40-50 kDa; cat. no. 4233), cyclin B1 (55 kDa; cat. no. 12231), cyclin D1 (36 kDa; cat. no. 55506), CD133 (133 kDa; cat. no. 64326), Sox2 (35 kDa; cat. no. 3579), Oct4 (45 kDa; cat. no. 2750), Nanog (42 kDa; cat. no. 3580), integrin- $\alpha 6$ (125,150 kDa; cat. no. 3750), ALDH1A1 (55 kDa; cat. no. 12035), rabbit IgG (cat. no. 7074), and mouse IgG (cat. no. 7076) were purchased from Cell Signaling Technology. Antibody against p21 (21 kDa; cat. no. sc-397) was obtained Santa Cruz Biotechnology, Inc.. Antibodies against $\beta$-actin (42 kDa; cat. no. ab6276) and $\mathrm{Bad}(22 \mathrm{kDa}$; cat. no. ab62465) were purchased from Abcam.
Preparation of CECU. Dried C. unshiu Markovich peels were purchased from Yeong-cheon Herbal Wholesale Market. A voucher specimen (NCB-CECU-2018) was deposited in the Department of Pharmaceutical Engineering and Biotechnology, Sun Moon University. It was extracted with $100 \%$ ethanol for $24 \mathrm{~h}$ and concentrated in vacuo. The extract was partitioned between chloroform and distilled water in a 1:1 ratio to obtain the chloroform fraction. CECU was prepared at a concentration of $100 \mathrm{mg} / \mathrm{ml}$ using DMSO.

Cell culture. HeLa, CaSki, and SiHa human cervical cancer cell lines were purchased from the Korean Cell Line Bank. Cells were grown in DMEM containing 10\% FBS and 1\% penicillin-streptomycin-amphotericin $\mathrm{B}$ and maintained at $37^{\circ} \mathrm{C}$ in a humidified $5 \% \mathrm{CO}_{2}$ incubator (Thermo Fisher Scientific, Inc.). 267B1 human normal prostate epithelial cells were kindly provided by the Anticancer Agent Research Center in Korea Research Institute of Bioscience and Biotechnology and were grown in RPMI-1640 supplemented with 10\% FBS and $1 \%$ antibiotics. HeLa-derived cancer stem-like cells were cultured in DMEM/F12 supplemented with 1X B-27, $5 \mu \mathrm{g} / \mathrm{ml}$ heparin, $2 \mathrm{mM}$ L-glutamine, $20 \mathrm{ng} / \mathrm{ml} \mathrm{bFGF}, 20 \mathrm{ng} / \mathrm{ml} \mathrm{EGF}$, and $1 \%$ penicillin/streptomycin.

Total polyphenol content. The total polyphenol content of CECU was estimated using Folin-Ciocalteu reagent (Sigma-Aldrich; Merck KGaA). CECU (100 $\mu 1)$ and Folin-Ciocalteu reagent $(60 \mu \mathrm{l})$ were mixed for $5 \mathrm{~min}$, and then $600 \mu \mathrm{l}$ of $2 \% \mathrm{Na}_{2} \mathrm{CO}_{3}$ was added. After incubation in the dark for $2 \mathrm{~h}$, the absorbance was measured at $750 \mathrm{~nm}$ using a multimode microplate reader (BioTek, Inc.). A calibration curve of gallic acid was constructed and linearity was obtained in the range of $0-0.9 \mathrm{mg} / \mathrm{ml}$. The total phenolic content in CECU was expressed as milligram of gallic acid equivalent (mg GAE/g extract) using the standard curve.

HPLC analysis. HPLC was performed to identify the content of hesperidin and heperetin in CECU. The reference compounds were diluted with $\mathrm{MeOH}$ to a concentration of $0.5 \mathrm{mg} / \mathrm{ml}$, and CECU was prepared to a concentration of $20 \mathrm{mg} / \mathrm{ml}$. The prepared samples $(10 \mu \mathrm{l})$ were injected and analyzed by HPLC-PDA (Shimadzu LC-2030C; SPD-M20A Detector) using a reverse phase C18 column [Mightysil-RP-18 GP, 250x4.6 mm (5 $\mu \mathrm{m})$; Kanto Chemical] with oven temperature of $40^{\circ} \mathrm{C}$ at $288 \mathrm{~nm}$. The binary mobile phases were composed of solvent A $(0.025 \%$ trifluoroacetic acid in HPLC-grade water) and solvent $\mathrm{B}$ ( $100 \%$ acetonitrile). The flow rate of the mobile phase was maintained at $1 \mathrm{ml} / \mathrm{min}$ for the $35 \mathrm{~min}$ gradient program. The program used was as follows: $5 \% \mathrm{~B}$ to $100 \% \mathrm{~B}$ (linear gradient, $0-25 \mathrm{~min}), 100 \% \mathrm{~B}(25-27 \mathrm{~min}), 100 \% \mathrm{~B}$ to $5 \% \mathrm{~B}(27-32 \mathrm{~min})$, and $5 \% \mathrm{~B}$ (32-35 $\mathrm{min})$.

Cell proliferation assay. HeLa, SiHa, CaSki and 267B1 cells ( $2 \times 10^{3}$ cells/well) were seeded in a 96 -well culture plate. After a $24 \mathrm{~h}$ incubation, cells were treated with various concentrations of CECU. After incubation for $72 \mathrm{~h}, 50 \mu \mathrm{l}$ of MTT solution $(2 \mathrm{mg} / \mathrm{ml})$ was added to each well. Cells were incubated for $3 \mathrm{~h}$ and then dissolved in $100 \mu \mathrm{l}$ of DMSO per well. Absorbance was measured at a wavelength of $540 \mathrm{~nm}$ using a microplate reader (BioTek). The $\mathrm{IC}_{50}$ values from the obtained data were 
analyzed using the curve-fitting program GraphPad Prism 5 (GraphPad Software).

Colony formation assay. HeLa cells $\left(3 \times 10^{2}\right.$ cells/well) were seeded in a 6-well culture plate and treated with CECU. Cells were grown for 13 days, and formed colonies were fixed with $3.7 \%$ formaldehyde for $10 \mathrm{~min}$. After washing with PBS, the colonies were stained with $1 \mathrm{ml}$ of $0.5 \%$ crystal violet for 20 min. Stained colonies were washed with PBS, and the number of colonies was counted.

Wound healing assay. HeLa cells $\left(15 \times 10^{4}\right.$ cells/well) were seeded in a 24-well culture plate. After incubation for $24 \mathrm{~h}$, cells were scratched using a $10 \mu \mathrm{l}$ of pipette tip, washed with PBS, and treated with CECU in a medium containing $1 \%$ FBS. After a 72-h incubation, images were obtained under a $x 40$ optical microscope (Olympus). The number of cells that migrated into the gap was counted and results were presented as a percentage of control.

Migration assay. Cell migration was also assayed using a Transwell chamber system with polycarbonate filter inserts with a pore size of $8.0 \mu \mathrm{m}$ (Corning Costar). The lower side of the filter was coated with $10 \mu \mathrm{l}$ gelatin $(1 \mathrm{mg} / \mathrm{ml})$, and HeLa cells $\left(1 \times 10^{5}\right.$ cells/well $)$ were placed in the upper chamber of the filter. CECU was added to the lower chamber filled with a medium containing $1 \% \mathrm{FBS}$, and the chamber was incubated at $37^{\circ} \mathrm{C}$ for $24 \mathrm{~h}$. The cells were subsequently fixed with methanol and stained with hematoxylin and eosin. Images were obtained under a x100 optical microscope (Olympus), and the total number of cells that migrated the lower chamber of the filter was counted. Results were presented as a percentage of control.

Cell cycle analysis. Cell cycle analysis was performed using a Muse $^{\mathrm{TM}}$ cell cycle kit (Merck Millipore) according to the manufacturer's instructions. Briefly, HeLa cells ( $3 \times 10^{5}$ cells/dish) were seeded in a 60-mm culture dish and treated with CECU for $24 \mathrm{~h}$. The cells were collected, washed with PBS, and fixed with cold $70 \%$ ethanol. After overnight storage at $-20^{\circ} \mathrm{C}$, ethanol was removed, and the cells were washed with PBS. Further, $200 \mu \mathrm{l}$ of Muse cell cycle reagent was added and reacted in the dark for $30 \mathrm{~min}$. The percentage of cells in G0/G1, S and G2/M phases was then calculated using Muse cell analyzer and Muse analysis software (MuseSoft_V1.8.0.3; Luminex Corporation). The Muse cell cycle software module displays the data in two plots: A dot plot displaying DNA Content Index vs. Cell Size Index for setting the gate and a histogram displaying DNA Content Index vs. Count for assessing the percentage of cells in each phase.

Apoptosis analysis. HeLa cells $\left(5 \times 10^{5}\right.$ cells/dish) were placed in a $60-\mathrm{mm}$ culture dish and treated with CECU for $24 \mathrm{~h}$. The cells were harvested, washed with PBS, and stained with Annexin V-FITC and PI according to the manufacturer's instructions (Invitrogen; Thermo Fisher Scientific, Inc.). Stained cells were analyzed by flow cytometry (Cyto FLEX; Beckman Coulter).

ROS analysis. HeLa cells $\left(1 \times 10^{5}\right.$ cells/well) were seeded in a 96-black well culture plate and treated with CECU for
$30 \mathrm{~min}$. Cells were then incubated with $10 \mu \mathrm{M}$ of 2',7'-dichlorodihydrofluorescein diacetate (DCFH-DA; Sigma-Aldrich; Merck $\mathrm{KGaA}$ ) for $20 \mathrm{~min}$ and washed with PBS. The fluorescence intensity of DCF was detected using a multimode microplate reader (BioTek) at excitation and emission wavelengths of 495 and $529 \mathrm{~nm}$, respectively.

DAPI staining. HeLa cells $\left(5 \times 10^{4}\right.$ cells/well $)$ were seeded in a 24-well culture plate and treated with CECU for $24 \mathrm{~h}$. Cells were fixed with $3.7 \%$ formaldehyde for $10 \mathrm{~min}$. Nuclei were stained with $4 \mu \mathrm{g} / \mathrm{ml}$ of 4',6-diamidine-2'-phenylindole dihydrochloride (DAPI) for $30 \mathrm{~min}$ and washed with PBS. The nuclear morphology of cells was captured using a fluorescence microscope (Korea Lab Tech).

ATP-monitoring luminescence assay. ATPlite Luminescence Assay System (PerkinElmer) was used to quantitatively evaluate the proliferation of HeLa cancer stem-like cells. Cells $\left(3 \times 10^{3}\right.$ cells/well) were seeded in a 96-white well culture plate using serum-free media with EGF and bFGF and treated with CECU, hesperidin, and hesperetin for 7 days. Following the addition of $50 \mu \mathrm{l}$ of substrate solution to each well, the culture plate was shaken for $5 \mathrm{~min}$ and incubated in the dark for $10 \mathrm{~min}$. Luminescence was detected using a multimode microplate reader (BioTek).

Tumorsphere-forming assay. HeLa cancer stem-like cells were cultured in Dulbecco's modified Eagle's medium/nutrient mixture F-12 (DMEM/F12; Gibco; Thermo Fisher Scientific, Inc.) containing 1X B-27 serum-free supplement (Gibco; Thermo Fisher Scientific, Inc.), $5 \mu \mathrm{g} / \mathrm{ml}$ heparin (Sigma-Aldrich; Merck KGaA), 2 mM L-glutamine (Gibco; Thermo Fisher Scientific, Inc.), $20 \mathrm{ng} / \mathrm{ml}$ epidermal growth factor (EGF; Gibco; Thermo Fisher Scientific, Inc.), $20 \mathrm{ng} / \mathrm{ml}$ basic fibroblast growth factor (bFGF; Gibco; Thermo Fisher Scientific, Inc.) and $1 \%$ penicillin/streptomycin (Gibco; Thermo Fisher Scientific, Inc.). The serum-free media with EGF and bFGF were added to the cells twice a week. Cultured tumorspheres were passed every 7 days by dissociating with Accutase (Millipore). To evaluate the effect of CECU on the tumorsphere-forming ability of HeLa cancer stem-like cells, the cells $\left(5 \times 10^{2}\right.$ cells/well) were seeded in a 96-well culture plate using serum-free media with EGF and bFGF $(200 \mu \mathrm{l} /$ well $)$ and treated with $\operatorname{CECU}(0,4,8,16,31$ and $63 \mu \mathrm{g} / \mathrm{ml})$. After incubation for 7 days without changing the media, the number of tumorspheres that are $>75 \mu \mathrm{m}$ in diameter was counted under a x200 optical microscope (Olympus). Results were presented as a percentage of control.

Western blot analysis. Cells were lysed using RIPA buffer (Sigma-Aldrich; Merck KGaA) supplemented with a protease inhibitor cocktail (Roche Diagnostics), on ice. Extract protein concentrations were determined using a BCA Protein Assay kit (Pierce; Thermo Fisher Scientific, Inc.). Equal amounts of cell lysate (40 $\mu \mathrm{g} /$ lane) were separated by $10 \%$ sodium dodecyl sulfate-polyacrylamide gel electrophoresis (SDS-PAGE), and the separated proteins were transferred to polyvinylidene difluoride (PVDF) membranes (EMD Millipore) using standard electroblotting procedures. Blots were blocked in Tris-buffered saline with Tween-20 (TBST) containing 

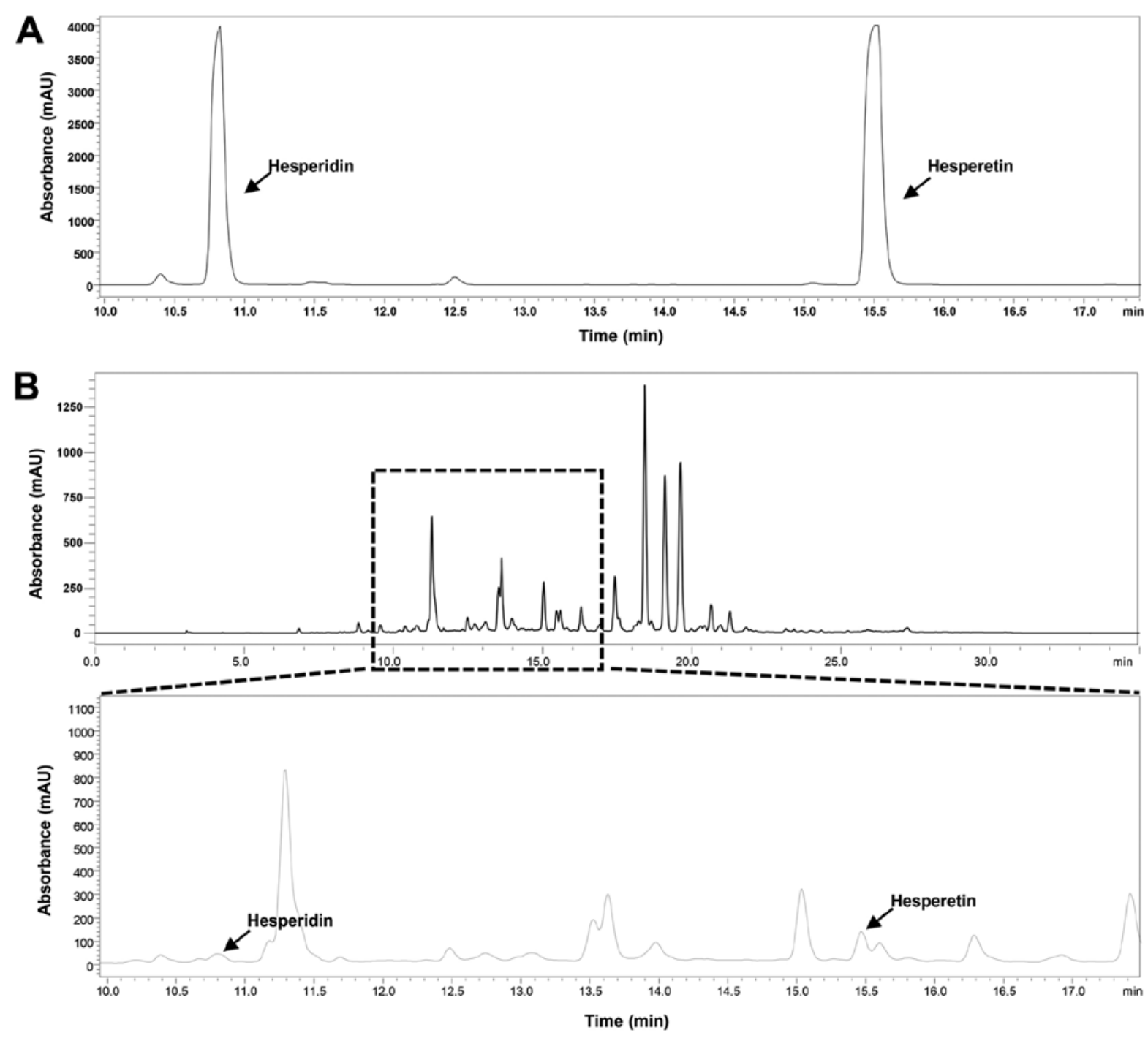

Figure 1. HPLC analysis of CECU. (A) The two reference compounds (hesperidin and hesperetin) and (B) CECU were analyzed by HPLC. HPLC, high-performance liquid chromatography; CECU, C. unshiu Markovich peel.

$5 \%$ skim milk at room temperature for $1 \mathrm{~h}$ and immunolabeled with primary antibodies against p53 (dilution 1:2,000), p21 (dilution 1:500), phospho-AKT (dilution 1:2,000), AKT (dilution 1:2,000), phospho-ERK1/2 (dilution 1:2,000), ERK1/2 (dilution 1:2,000), Bcl-2 (dilution 1:2,000), Bcl-XL (dilution 1:2,000), Bad (dilution 1:2,000), Bax (dilution 1:2,000), cleaved caspase-3 (dilution 1:2,000), cleaved caspase-9 (dilution 1:2,000), cleaved caspase-8 (dilution 1:2,000), PARP (dilution 1:2,000), DR5 (dilution 1:2,000), Fas (dilution 1:2,000), cyclin B1 (dilution 1:2,000), cyclin D1 (dilution 1:2,000), CD133 (dilution 1:2,000), Sox 2 (dilution 1:2,000), Oct4 (dilution 1:2,000), Nanog (dilution 1:2,000), integrin- $\alpha 6$ (dilution 1:2,000), ALDH1A1 (dilution 1:2,000), and $\beta$-actin (dilution $1: 10,000$ ) overnight at $4^{\circ} \mathrm{C}$. After washing with TBST three times, membranes were incubated with horseradish peroxidase-conjugated anti-rabbit (dilution $1: 3,000$ ) or anti-mouse (dilution 1:3,000) secondary antibody for $1 \mathrm{~h}$ at room temperature. Immunolabeling was detected using an enhanced chemiluminescence (ECL) kit (Bio-Rad Laboratories, Inc.) according to the manufacturer's instructions. The band density was analyzed using ImageJ software (version 1.5; NIH).
Statistical analysis. Results are expressed as the mean \pm standard deviation (SD). Differences among groups were analyzed using analysis of variance (ANOVA) with SPSS statistics package (SPSS 9.0; SPSS, Inc.). Post hoc analysis was carried out using Tukey's test. A P-value of $<0.05$ was considered to indicate a statistically significant difference.

\section{Results}

Analysis of the composition of CECU. Polyphenols have shown numerous biological activities resulting in the prevention and treatment of human diseases, including cancers (22). To evaluate the phytochemical composition of CECU, the total phenolic content was determined using the Folin-Ciocalteu method. CECU contained $8.3 \mathrm{mg}$ GAE/g of polyphenols.

Hesperidin and its aglycone, hesperetin, are the main bioactive phytochemicals found in citrus species (16). To determine the content of these ingredients in CECU, the reference compounds and CECU were subjected to HPLC analysis. The detection wavelength for the compounds was $288 \mathrm{~nm}$. The HPLC chromatogram of CECU detected hesperidin and hesperetin at retention times of 10.82 and $15.53 \mathrm{~min}$, 



B

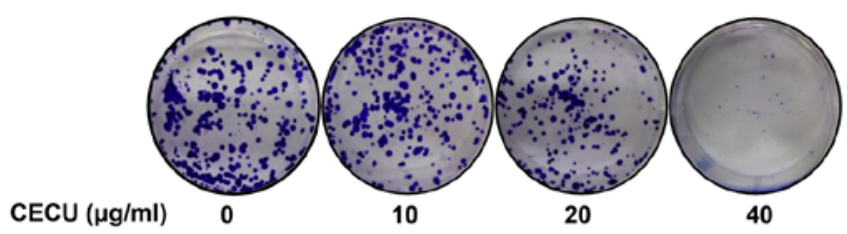

C

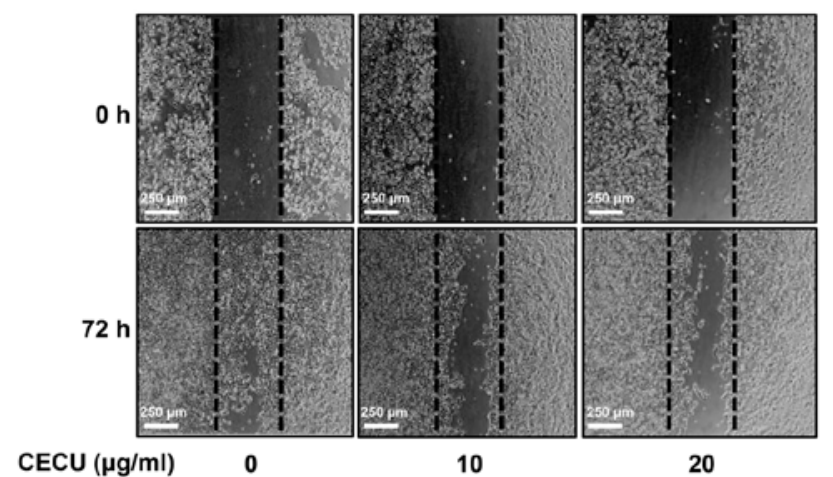

D

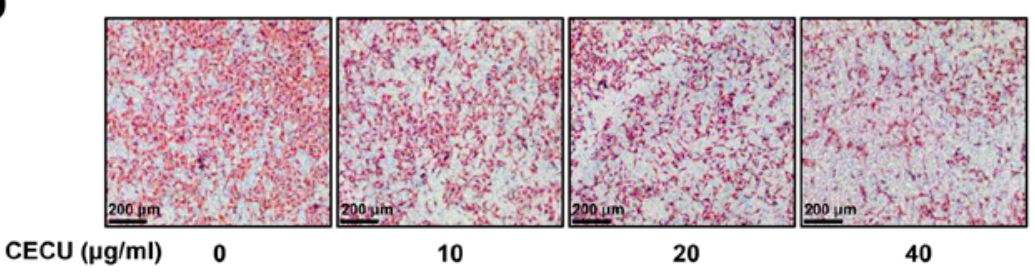

CaSki

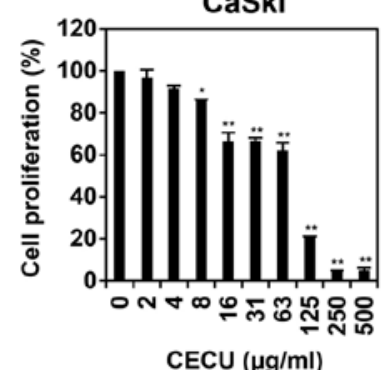

$\operatorname{CECU}(\mu \mathrm{g} / \mathrm{ml})$
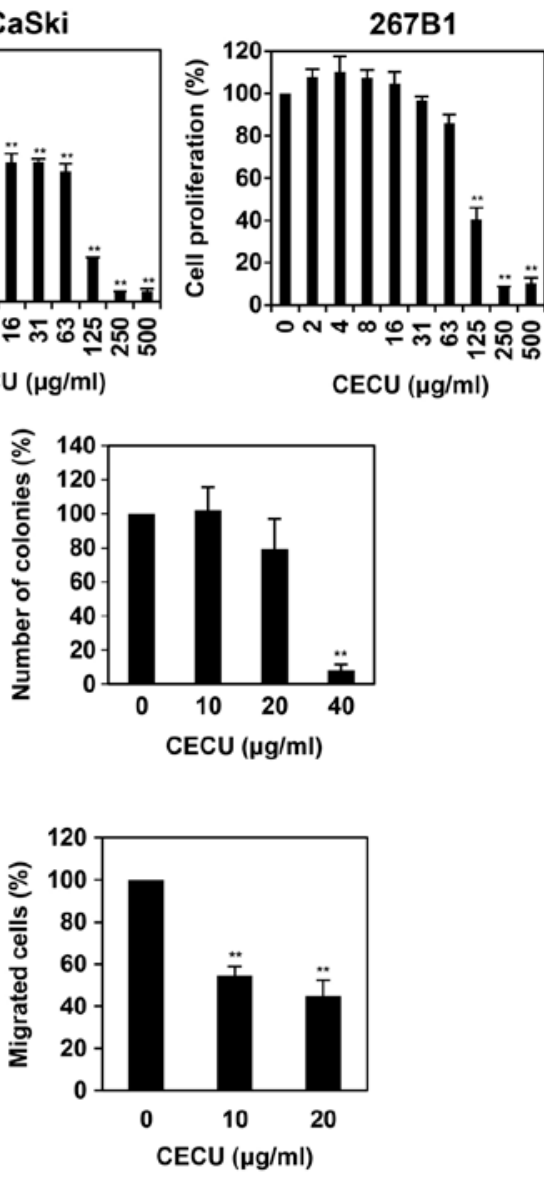

Figure 2. Effects of CECU on the proliferation and migration of HeLa cells. (A) Effect of CECU on the proliferation of HeLa, SiHa, CaSki and 267B1 cells. Cells were treated with increasing concentrations of CECU $(0-500 \mu \mathrm{g} / \mathrm{ml})$ for $72 \mathrm{~h}$ and cell proliferation was measured using a MTT assay. (B) Effect of CECU on the colony forming ability of HeLa cells. Cells were incubated in the absence or presence of CECU (10,20 and $40 \mu \mathrm{g} / \mathrm{ml})$ for 13 days. Cell colonies were detected by crystal violet staining. (C) Effect of CECU on the migration of HeLa cells by wound healing assay. Cells were incubated in the absence or presence of CECU $(10$ and $20 \mu \mathrm{g} / \mathrm{ml})$ for $72 \mathrm{~h}$. The cells that migrated into the gap were counted under an optical microscope. Dotted black lines indicate the edge of the gap at $0 \mathrm{~h}$. (D) Effect of CECU on the migration of HeLa cells by Transwell assay. Cells were placed in the upper chamber, and CECU (10, 20 and $40 \mu \mathrm{g} / \mathrm{ml}) \mathrm{was}$ added to the lower chamber. The cells that migrated the lower chamber of the filter after incubation for $24 \mathrm{~h}$ were stained and counted under an optical microscope. ${ }^{*} \mathrm{P}<0.01$ and ${ }^{* *} \mathrm{P}<0.001$ vs. the control. Each value represents the mean $\pm \mathrm{SD}$ from three independent experiments. CECU, C. unshiu Markovich peel.

respectively (Fig. 1). The estimated content of hesperidin and hesperetin in CECU was 0.739 and $1.641 \%$, respectively.

Effects of CECU on the proliferation and migration of HeLa cells. To examine whether CECU affects the proliferation of cervical cancer cells, three different cervical cancer cell lines were treated with CECU $(0-500 \mu \mathrm{g} / \mathrm{ml})$ for $72 \mathrm{~h}$. Cell proliferation was then evaluated by the MTT assay. As shown in Fig. 2A, CECU treatment inhibited the proliferation of HeLa, SiHa and CaSki cells in a dose-dependent manner, with $\mathrm{IC}_{50}$ values of $58.95,73.41$ and $69.63 \mu \mathrm{g} / \mathrm{ml}$, respectively. Notably, CECU showed the highest inhibitory effect on the proliferation of HeLa cells. We further evaluated the effect of
CECU on the proliferation of 267B1 human normal prostate epithelial cells. CECU inhibited the proliferation of 267B1 cells with an $\mathrm{IC}_{50}$ value of $114.7 \mu \mathrm{g} / \mathrm{ml}$, indicating that CECU suppresses the proliferation of cervical cancer cells more sensitively compared to normal cells (Fig. 2A). Based on these results, we further assessed the inhibitory effects of CECU on the proliferative and migratory abilities of HeLa cells at concentrations ranging from $10-80 \mu \mathrm{g} / \mathrm{ml}$.

Next, we evaluated the effect of CECU on the colony formation of HeLa cells. Treatment with CECU suppressed the clonogenic proliferation of HeLa cells in a dose-dependent manner (Fig. 2B). In particular, the colony-forming ability of the cells was remarkably decreased at $40 \mu \mathrm{g} / \mathrm{ml}$ of CECU. 
A

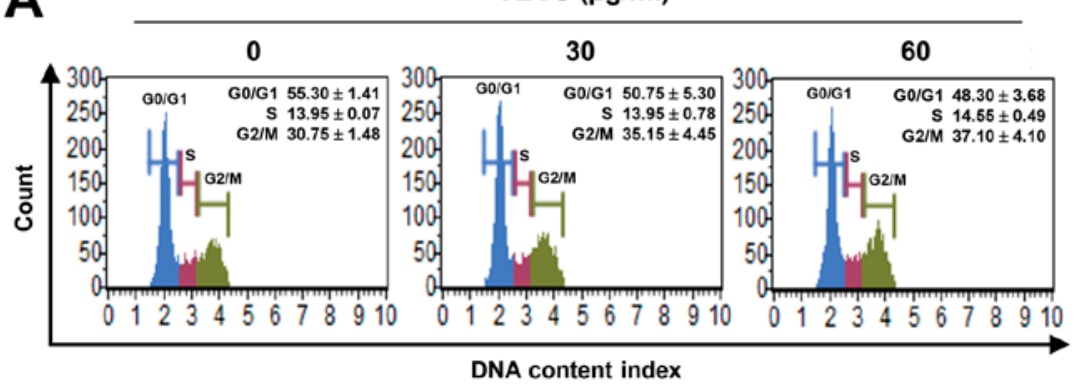

B



$\operatorname{CECU}(\mu \mathrm{g} / \mathrm{ml})$

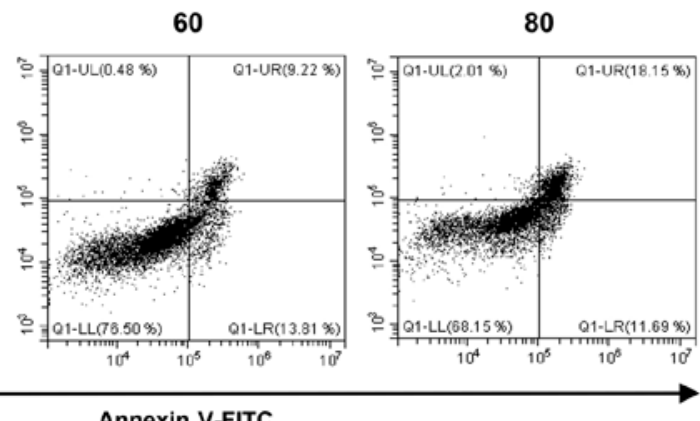

Annexin V-FITC

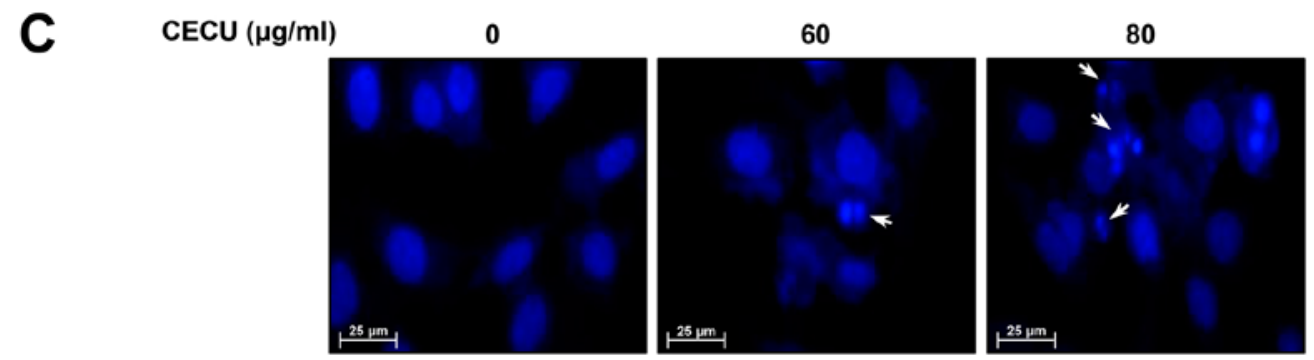

Figure 3. Effects of CECU on the cell cycle and apoptotic cell death of HeLa cells. (A) The cell cycle distribution of HeLa cells was evaluated using a Muse cell analyzer after treatment with CECU (30 and $60 \mu \mathrm{g} / \mathrm{ml})$ for $24 \mathrm{~h}$. (B) HeLa cells were treated with CECU (60 and $80 \mu \mathrm{g} / \mathrm{ml})$ for $24 \mathrm{~h}$. Apoptotic cells were determined by flow cytometry following Annexin V-FITC and propidium iodide (PI) dual labeling. (C) HeLa cells were treated with CECU (60 and $80 \mu \mathrm{g} / \mathrm{ml})$ for $24 \mathrm{~h}$. Changes in nuclear morphology were monitored by DAPI staining under a fluorescence microscope. The CECU-treated cells showed condensed and fragmented nuclei (indicated by white arrows). ${ }^{*} \mathrm{P}<0.01$, and ${ }^{* *} \mathrm{P}<0.001$ vs. the control. Each value represents the mean \pm SD from three independent experiments. CECU, C. unshiu Markovich peel.

To confirm the effect of CECU on the migration ability of HeLa cells, a monolayer wound healing assay was performed. Wound closure by HeLa cell migration was observed after $72 \mathrm{~h}$ of incubation. Treatment with CECU (10 and $20 \mu \mathrm{g} / \mathrm{ml})$ significantly reduced the migration of HeLa cells compared with the untreated control (Fig. 2C).

We further examined the effect of CECU on the migration of HeLa cells using Transwell chamber inserts. As shown in Fig. 2D, CECU treatment $(10,20$ and $40 \mu \mathrm{g} / \mathrm{ml})$ led to significant reduction of cell migration in HeLa cells. These results demonstrate that CECU effectively inhibits the proliferation and migration of cervical cancer cells.

Effects of CECU on cell cycle distribution and apoptosis in HeLa cells. To evaluate whether CECU inhibits the proliferation of HeLa cells by regulating the cell cycle, we examined the effect of CECU on cell cycle distribution using a Muse cell analyzer. Compared with the untreated control cells, treatment with CECU increased the G2/M phase cell population, while decreasing the
G0/G1 phase cell population (Fig. 3A). These data indicate that CECU caused G2/M phase arrest in HeLa cells.

To further investigate whether the CECU-induced proliferation inhibition is associated with apoptosis induction, CECU-treated HeLa cells were stained with Annexin V-FITC and PI and then analyzed by flow cytometry. After treatment with CECU, the proportion of early and late apoptotic cells increased compared to that of untreated control cells (Fig. 3B). Consequently, CECU exhibited a dose-dependent apoptosis-inducing effect in HeLa cells.

To confirm whether CECU causes morphological changes related to apoptosis in HeLa cells, DAPI staining was performed. As shown in Fig. 3C, CECU treatment resulted in nuclear condensation and fragmentation. These results demonstrate that CECU inhibits the proliferation of HeLa cells through the induction of cell cycle arrest and apoptosis.

Effects of CECU on apoptosis-related pathways in HeLa cells. The PI3K/AKT and the Ras/MEK/ERK pathways contribute 

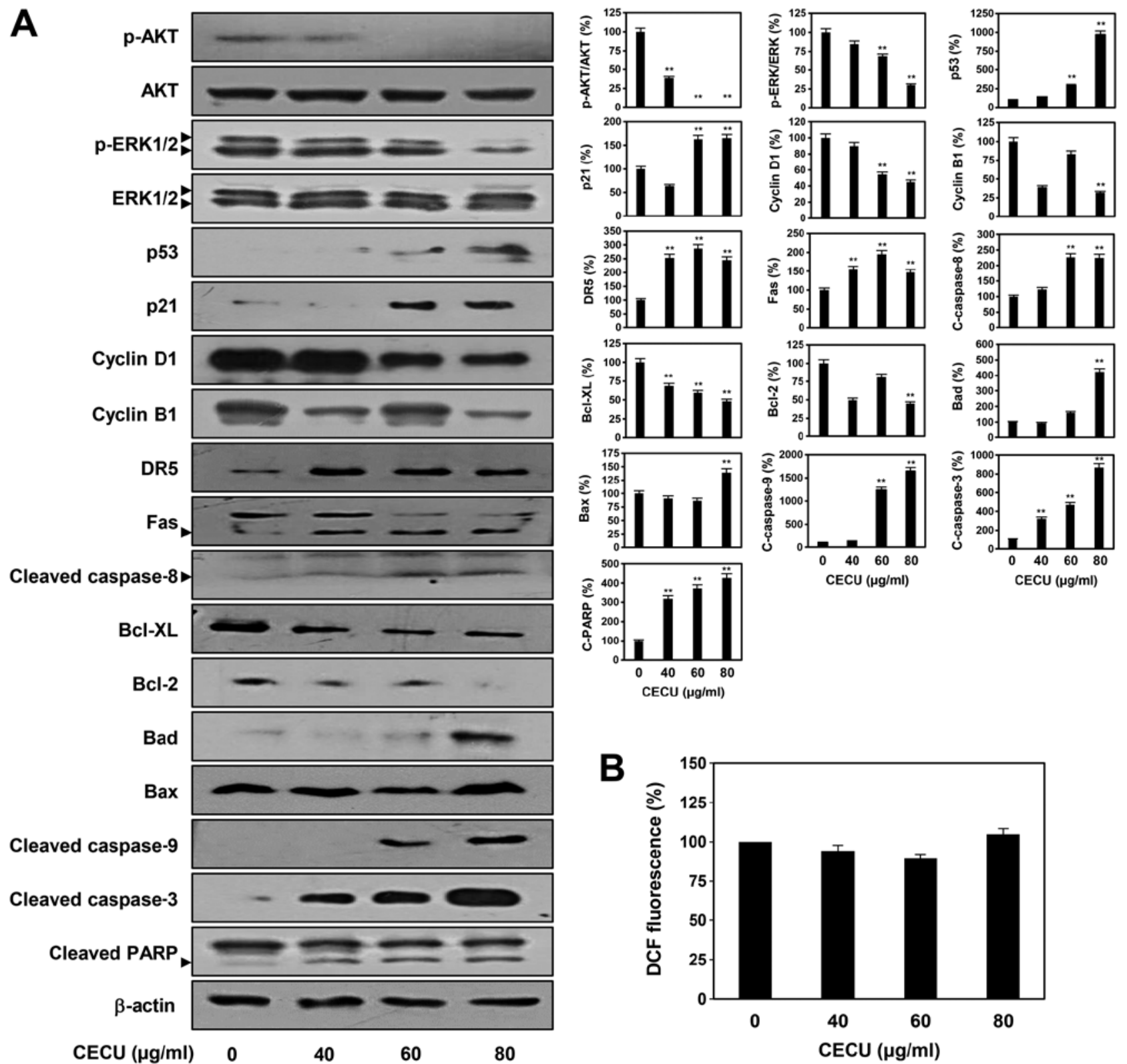

Figure 4. Effects of CECU on apoptosis-related pathways in HeLa cells. (A) HeLa cells were treated with CECU (40, 60 and $80 \mu \mathrm{g} / \mathrm{ml})$ for $24 \mathrm{~h}$ and the protein levels were detected by western blot analysis using specific antibodies. $\beta$-actin levels were used as an internal control. Arrowheads indicate bands that correspond to specific proteins. (B) Effect of CECU on ROS generation in HeLa cells. Cells were treated with CECU (40, $60 \mathrm{and} 80 \mu \mathrm{g} / \mathrm{ml})$ for $30 \mathrm{~min}$. Intracellular ROS levels were detected using DCFH-DA. ${ }^{* *} \mathrm{P}<0.001$ vs. the control. Each value represents the mean $\pm \mathrm{SD}$ from three independent experiments. CECU, C. unshiu Markovich peel; ROS, reactive oxygen species; DCFH-DA, 2',7'-dichlorodihydrofluorescein diacetate.

to the survival and proliferation of cervical cancer cells (23). To elucidate the molecular mechanism by which CECU inhibits the proliferation of HeLa cells, we first examined whether CECU regulates the activation of AKT and ERK, the key effectors of these signaling pathways. Treatment with CECU led to a significant downregulation of AKT and ERK1/2 phosphorylation without affecting total protein levels in HeLa cells (Fig. 4A).

Activation of the tumor suppressor protein p53 arrests the cell cycle at the G2/M phase. Cell cycle arrest by p53 is mainly mediated by the transcriptional activation of p21/WAF1 (24). Thus, we examined the effect of CECU on the expression of p53 and p21. Results showed that treatment with CECU markedly elevated the expression of p53 and p21 in HeLa cells (Fig. 4A). Moreover, CECU decreased the expression levels of cyclin B1 and cyclin D1, which are implicated in the regulation of $\mathrm{G} 2 / \mathrm{M}$ phase transition (Fig. 4A).

Cell apoptosis can be induced either through death receptor-mediated extrinsic pathways or mitochondria-mediated intrinsic pathways $(25,26)$. We therefore assessed whether CECU affects these apoptotic pathways in HeLa cells. Treatment with CECU clearly increased the expression levels of death receptors, DR5 and Fas as well as their downstream apoptosis effector, the active form of caspase- 8 (Fig. 4A). Furthermore, among the Bcl-2 family members that are involved in the intrinsic apoptotic pathway, the expression of anti-apoptotic proteins such as Bcl-XL and Bcl-2 were downregulated by CECU treatment, whereas the levels of pro-apoptotic proteins including Bad and Bax were upregulated (Fig. 4A). Consequently, the expression of the downstream apoptosis effector, caspase-9 was activated. By 

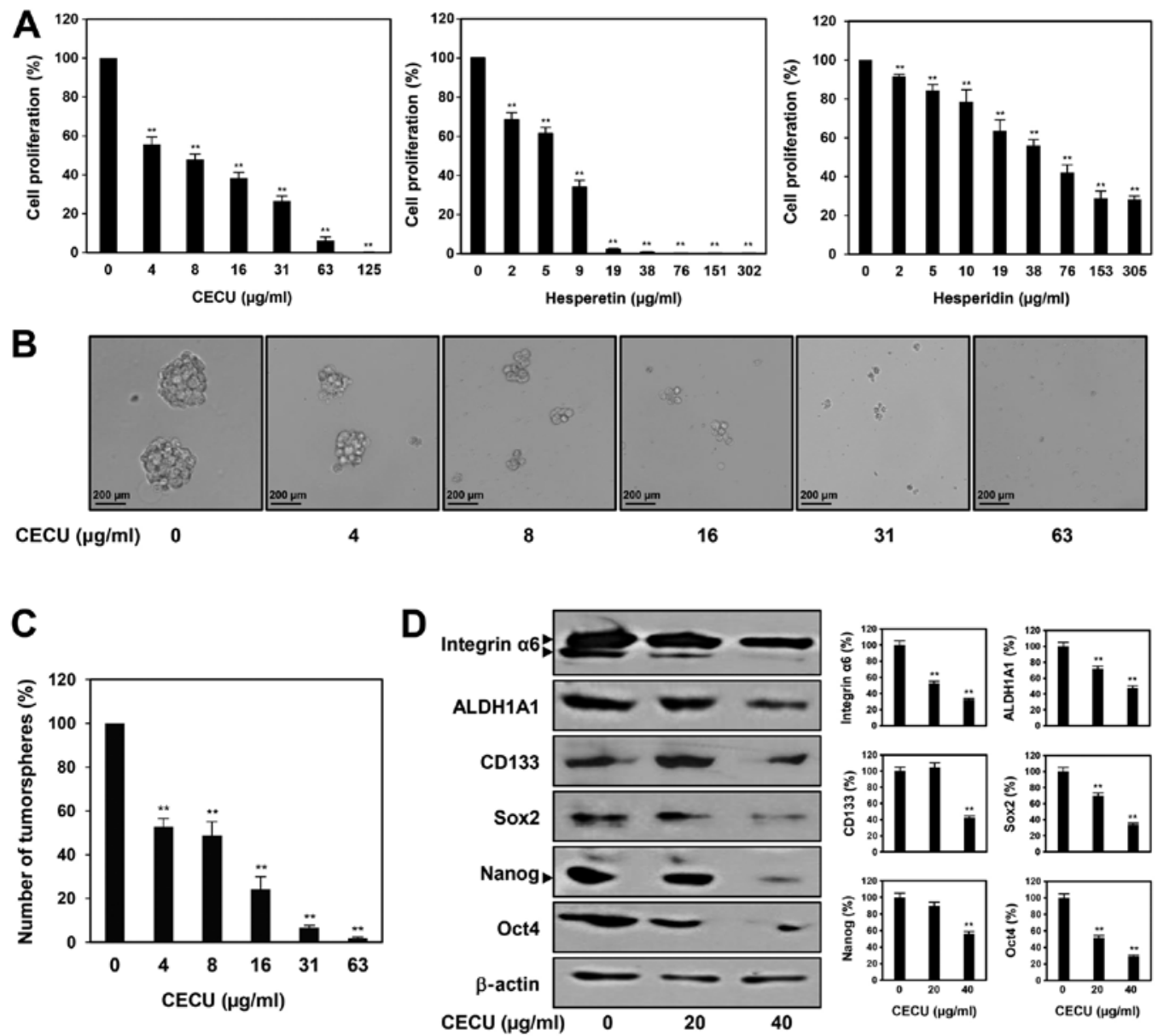

Figure 5. Effects of CECU on the cancer stem-like features of HeLa cells. (A) Effect of CECU on the proliferation of HeLa cancer stem-like cells. Cells were treated with increasing concentrations of CECU, hesperetin, and hesperidin and incubated with CSC culture media for 7 days. Cell proliferation was measured by the ATPlite luminescence assay. (B and C) Effect of CECU on the tumorsphere-forming ability of HeLa cancer stem-like cells. (B) The size and (C) number of tumorspheres were confirmed under an optical microscope. (D) Effect of CECU on the expression of cancer stemness biomarkers in HeLa cancer stem-like cells. Cells were treated with CECU (20 and $40 \mu \mathrm{g} / \mathrm{ml})$ for $48 \mathrm{~h}$, and the protein levels were detected by western blot analysis using specific antibodies. $\beta$-actin levels were used as an internal control. Arrowheads indicate bands that correspond to specific proteins. ${ }^{* *} \mathrm{P}<0.001$ vs. the control. Each value represents the mean \pm SD from three independent experiments. CECU, C. unshiu Markovich peel; CD, clusterof differentiation; CSC, cancer stem cells.

regulating the extrinsic and intrinsic apoptotic pathways, CECU triggered the activation of the critical executioner of apoptosis caspase- 3 and its substrate, PARP.

Reactive oxygen species (ROS) play an important role in the induction of apoptosis (27). Thus, we further evaluated whether the apoptosis-inducing effect of CECU is mediated by ROS in HeLa cells. Treatment with CECU did not cause a significant change in ROS generation, indicating that the apoptosis-inducing effect of CECU was ROS-independent (Fig. 4B). Taken together, these findings suggest that the inhibition of HeLa cell proliferation by CECU may be associated with the inactivation of AKT and ERK signaling, upregulation of p53 and p21, downregulation of cyclin B1 and cyclin D1, and activation of ROS-independent apoptotic pathways.

Effects of CECU on cancer stem-like features of HeLa cells. To assess the potential of CECU in suppressing cervical CSCs, we investigated the effects of CECU on the cancer stem-like properties of HeLa cells. The CSC population in HeLa cells was enriched through spheroid culture using serum-free media with EGF and bFGF $(28,29)$. As shown in Fig. 5A, treatment with CECU inhibited the proliferation of HeLa cancer stem-like cells in a dose-dependent manner. We also evaluated whether hesperidin and hesperetin are the possible active ingredients contributing to the antiproliferative activity of CECU against cervical CSCs. The two compounds suppressed the proliferation of HeLa cancer stem-like cells in a dose-dependent manner (Fig. 5A). Notably, hesperetin showed a better proliferation inhibitory effect compared to hesperidin in these cells. In addition, the clonogenic proliferation of HeLa cancer stem-like cells was remarkably suppressed by treatment with CECU (Fig. 5B and C). CECU treatment reduced the size and number of tumorspheres.

We further examined whether CECU regulates the expression of key stemness-related markers in cervical CSCs. Treatment with CECU significantly decreased the expression levels of stemness regulators including Sox2, Nanog, Oct4, ALDH1A1, integrin- $\alpha 6$ and CD133, in HeLa cancer stem-like cells (Fig. 5D). These results suggest that CECU has therapeutic potential to eliminate cervical CSCs.

\section{Discussion}

Cervical cancer is one of the leading gynecological malignancies worldwide. Although chemotherapy is the main approach 
for the treatment of cervical cancer, it often causes many side effects, and cancer cells can become chemo-resistant $(1,2)$. Natural products are a good source of new, potent, and selective anticancer agents $(12,13)$. Accumulating evidence has shown that a variety of non-polar compounds found in the chloroform extracts of natural products possess potent anticancer activities $(30,31)$. In this study, we assessed, for the first time, the anticancer activity, and the underlying molecular mechanism of the chloroform extract of CECU, in HeLa human cervical cancer cells. CECU effectively inhibited the proliferation and migration of HeLa cells, even at concentrations that do not affect normal cells. The anticancer effect of CECU was mediated by induction of cell cycle arrest at the $\mathrm{G} 2 / \mathrm{M}$ phase via upregulation of p53 and p21 expression and downregulation of cyclin B1 and cyclin D1 expression as well as activation of death receptor-mediated extrinsic and mitochondria-mediated intrinsic apoptotic pathways. However, CECU did not increase intracellular ROS generation in HeLa cells, suggesting that it induces apoptosis of cervical cancer cells in a ROS independent manner. Furthermore, the proliferation inhibition of HeLa cells by CECU was mediated by the inactivation of AKT and ERK signaling. Therefore, CECU can be used as a complementary and alternative medicine for the prevention and treatment of cervical cancer.

Several recent studies have confirmed the apoptosis-promoting effect of CECU in different cancer cells. The ethanol extract of $C$. unshiu Markovich peel inhibited T24 bladder cancer cell proliferation by activating intrinsic and extrinsic apoptotic pathways via ROS-mediated inactivation of PI3K/AKT signaling (19). The water extract of $C$. unshiu Markovich peel induced apoptosis in MCF-7 and MDA-MB-231 breast cancer cells by activating both, the extrinsic and intrinsic apoptotic pathways through ROS-dependent activation of AMPK signaling $(20,21)$. The ethanol and water extracts showed cancer cell proliferation inhibitory activities at concentrations ranging from $200-800 \mu \mathrm{g} / \mathrm{ml}$ and $250-1,500 \mu \mathrm{g} / \mathrm{ml}$, respectively. It should be noted that the chloroform extract of C. unshiu Markovich peel, exhibits antiproliferative effects at concentrations ranging from $10-80 \mu \mathrm{g} / \mathrm{ml}$ and activates apoptosis in a ROS independent manner in HeLa cervical cancer cells, unlike the ethanol and water extracts. Citrus species, including $C$. unshiu Markovich, are known to contain various flavonoids such as naringin, hesperidin, and its aglycone hesperetin (16). These flavonoids have diverse biological activities, such as anti-inflammatory, anticancer, anti-obesity, antioxidant, antimicrobial, and anti-mutagenic properties $(32,33)$. Although we confirmed the presence of hesperidin and hesperetin in CECU by HPLC analysis, the non-aqueous extract may contain various non-polar bioactive substances different from the ingredients found in the ethanol and water extracts. Accordingly, differences in effective concentrations and mechanisms of action are expected to be due to differences in the composition of the extracts.

Moreover, for the first time, we evaluated the potential of CECU in suppressing the cancer stem-like features of HeLa cells. Cancer stem cells (CSCs), a small population of cancer cells with a capacity for self-renewal and differentiation potential, have been considered as a promising therapeutic target for cancer (34). CSCs contribute to multiple tumor malignancies, such as tumor metastasis and recurrence, chemotherapy and radiotherapy resistance, and genetic heterogeneity $(10,11)$. In our present study, cervical CSCs were cultured in 3D spheroid culture condition, which is known to better represent the in vivo cellular environment (35). Our results showed that CECU potently inhibited the proliferation and tumorsphere-forming ability of HeLa cancer stem-like cells. In addition, hesperidin and hesperetin suppressed the proliferation of HeLa CSCs, suggesting that these two compounds might be the possible active ingredients contributing to the antiproliferative activity of CECU against cervical CSCs. However, further identification of other active compounds in CECU is required to clearly understand the anticancer mechanism of CECU in cervical cancer cells. The biological characteristics of cervical CSCs are regulated by several key stemness-related biomarkers. Transcription factors, including Sox2, Oct4 and Nanog, play a critical role in the regulation of cervical CSC proliferation and maintenance $(36,37)$. CD133 and integrin- $\alpha 6$ are cell surface markers of cervical CSCs, which are related to self-renewal, tumorigenesis, and resistance to radiation therapy $(38,39)$. The activity of aldehyde dehydrogenase 1A1 (ALDH1A1) is associated with drug detoxification by aldehyde oxidation. ALDH1A1 eliminates oxidative stress and thus enhances the resistance of cervical CSCs to chemotherapeutic drugs $(40,41)$. Our results showed that CECU significantly suppressed the expression of cancer stemness regulators, including Sox2, Nanog, Oct4, ALDH1A1, integrin- $\alpha 6$ and CD133, in HeLa cancer stem-like cells. Therefore, CECU may have therapeutic potential to eradicate cervical CSCs. Taken together, our findings provide a new perspective on the anticancer activity and mechanism of action of the non-aqueous extract of CECU against cervical cancer cells. However, further in vivo experiments are required to be performed to support the therapeutic efficacy of CECU against cervical cancer.

\section{Acknowledgements}

Not applicable.

\section{Funding}

The current study was supported by Basic Science Research Program through the National Research Foundation of Korea (NRF) funded by the Ministry of Education (grant no. NRF-2016R1D1A1B03932956) and the NRF grant funded by the Ministry of Science and ICT (grant no. NRF-2019R1A2C1009033). This work was also supported by the Brain Korea 21 Plus Project, Republic of Korea.

\section{Availability of data and materials}

The datasets used and/or analyzed during the current study are available from the corresponding author on reasonable request.

\section{Authors' contributions}

HJJ conceived and designed the experiments. YSC and JMH performed the experiments and analyzed the data. YSC and HJJ wrote the paper. HJJ and YJK interpreted the data and revised the paper. All authors read and approved the final manuscript. 


\section{Ethics approval and consent to participate}

Not applicable.

\section{Patient consent for publication}

Not applicable.

\section{Competing interests}

The authors declare that they have no competing interests.

\section{References}

1. Schiffman M,Castle PE,Jeronimo J,Rodriguez AC and Wacholder S: Human papillomavirus and cervical cancer. Lancet 370: 890-907, 2007.

2. Liontos M, Kyriazoglou A, Dimitriadis I, Dimopoulos MA and Bamias A: Systemic therapy in cervical cancer: 30 years in review. Crit Rev Oncol Hematol 137: 9-17, 2019.

3. Pfeffer CM and Singh AT: Apoptosis: A target for anticancer therapy. Int J Mol Sci 19: E448, 2018.

4. Otto T and Sicinski P: Cell cycle proteins as promising targets in cancer therapy. Nat Rev Cancer 17: 93-115, 2017.

5. Hu Z, Ding W, Zhu D, Yu L, Jiang X, Wang X, Zhang C, Wang L, Ji T, Liu D, et al: TALEN-mediated targeting of HPV oncogenes ameliorates HPV-related cervical malignancy. J Clin Invest 125 : 425-436, 2015.

6. Arroyo M, Bagchi S and Raychaudhuri P: Association of the human papillomavirus type $16 \mathrm{E} 7$ protein with the S-phase-specific E2F-cyclin A complex. Mol Cell Biol 13: 6537-6546, 1993.

7. Ayob AZ and Ramasamy TS: Cancer stem cells as key drivers of tumour progression. J Biomed Sci 25: 20, 2018.

8. Feng D, Peng C, Li C, Zhou Y, Li M, Ling B, Wei H and Tian Z: Identification and characterization of cancer stem-like cells from primary carcinoma of the cervix uteri. Oncol Rep 22: 1129-1134, 2009.

9. Cooke SL, Temple J, Macarthur S,Zahra MA, Tan LT, Crawford RA, $\mathrm{Ng}$ CK, Jimenez-Linan M, Sala E and Brenton JD: Intra-tumour genetic heterogeneity and poor chemoradiotherapy response in cervical cancer. Br J Cancer 104: 361-368, 2011.

10. Ortiz-Sánchez E, Santiago-López L, Cruz-Domínguez VB, Toledo-Guzmán ME, Hernández-Cueto D, Muñiz-Hernández S, Garrido E, Cantú De León D and García-Carrancá A: Characterization of cervical cancer stem cell-like cells: Phenotyping, stemness, and human papilloma virus co-receptor expression. Oncotarget 7: 31943-31954, 2016.

11. Huang R and Rofstad EK: Cancer stem cells (CSCs), cervical CSCs and targeted therapies. Oncotarget 8: 35351-35367, 2017.

12. Lichota A and Gwozdzinski K: Anticancer activity of natural compounds from plant and marine environment. Int J Mol Sci 19: E3533, 2018.

13. Roy M, Mukherjee A, Sarkar R, Mukherjee S and Biswas J: In search of natural remediation for cervical cancer. Anticancer Agents Med Chem 15: 57-65, 2015.

14. Yang $\mathrm{CH}$ and Horwitz SB: Taxol ${ }^{\circledR}$ : The first microtubule stabilizing agent. Int J Mol Sci 18: 1733, 2017.

15. McCreight LJ, Bailey CJ and Pearson ER: Metformin and the gastrointestinal tract. Diabetologia 59: 426-435, 2016.

16. Kanaze FI, Bounartzi MI, Georgarakis $M$ and Niopas I: Pharmacokinetics of the citrus flavanone aglycones hesperetin and naringenin after single oral administration in human subjects. Eur J Clin Nutr 61: 472-477, 2007.

17. Min KY, Kim HJ, Lee KA, Kim KT and Paik HD: Antimicrobial activity of acid-hydrolyzed Citrus unshiu peel extract in milk J Dairy Sci 97: 1955-1960, 2014.

18. Oh YC, Cho WK, Jeong YH, Im GY, Yang MC, Hwang YH and Ma JY: Anti-inflammatory effect of Citrus Unshiu peel in LPS-stimulated RAW 264.7 macrophage cells. Am J Chin Med 40: 611-629, 2012.

19. Ahn KI, Choi EO, Kwon DH, HwangBo H, Kim MY, Kim HJ, Ji SY, Hong SH, Jeong JW, Park C, et al: Induction of apoptosis by ethanol extract of Citrus unshiu Markovich peel in human bladder cancer T24 cells through ROS-mediated inactivation of the PI3K/ Akt pathway. Biosci Trends 11: 565-573, 2017.
20. Kim MY, Choi EO, HwangBo H, Kwon DH, Ahn KI, Kim HJ, Ji SY, Hong SH, Jeong JW, Kim GY, et al: Reactive oxygen species-dependent apoptosis induction by water extract of Citrus unshiu peel in MDA-MB-231 human breast carcinoma cells. Nutr Res Pract 12: 129-134, 2018.

21. Kim MY, Bo HH, Choi EO, Kwon DH, Kim HJ, Ahn KI, Ji SY, Jeong JW, Park SH, Hong SH, et al: Induction of apoptosis by Citrus unshiu peel in human breast cancer MCF-7 cells: Involvement of ROS-dependent activation of AMPK. Biol Pharm Bull 41: 713-721, 2018.

22. Li AN, Li S, Zhang YJ, Xu XR, Chen YM and Li HB: Resources and biological activities of natural polyphenols. Nutrients 6: 6020-6047, 2014.

23. Li S, Ma YM, Zheng PS and Zhang P: GDF15 promotes the proliferation of cervical cancer cells by phosphorylating AKT1 and Erk1/2 through the receptor ErbB2. J Exp Clin Cancer Res 37: 80, 2018.

24. Al Bitar S and Gali-Muhtasib H: The role of the cyclin dependent kinase inhibitor p21cip1/waf1 in targeting cancer: Molecular mechanisms and novel therapeutics. Cancers (Basel) 11: E1475, 2019.

25. Fulda S and Debatin KM: Extrinsic versus intrinsic apoptosis pathways in anticancer chemotherapy. Oncogene 25: 4798-4811, 2006.

26. Llambi F and Green DR: Apoptosis and oncogenesis: Give and take in the BCL-2 family. Curr Opin Genet Dev 21: 12-20, 2011.

27. Redza-Dutordoir M and Averill-Bates DA: Activation of apoptosis signalling pathways by reactive oxygen species. Biochim Biophys Acta 1863: 2977-2992, 2016

28. Shin HJ, Han JM, Choi YS and Jung HJ: Pterostilbene suppresses both cancer cells and cancer stem-like cells in cervical cancer with superior bioavailability to resveratrol. Molecules 25: E228, 2020.

29. Jung N, Kwon HJ and Jung HJ: Downregulation of mitochondrial UQCRB inhibits cancer stem cell-like properties in glioblastoma. Int J Oncol 52: 241-251, 2018.

30. Vafaee K, Dehghani S, Tahmasvand R, Saeed Abadi F, Irian S and Salimi M: Potent antitumor property of Allium bakhtiaricum extracts. BMC Complement Altern Med 19: 116, 2019.

31. Yan Z, Feng J, Peng J, Lai Z, Zhang L, Jin Y, Yang H, Chen W and Lin J: Chloroform extract of Hedyotis diffusa Willd inhibits viability of human colorectal cancer cells via suppression of AKT and ERK signaling pathways. Oncol Lett 14: 7923-7930, 2017.

32. Panche AN, Diwan AD and Chandra SR: Flavonoids: An overview. J Nutr Sci 5: e47, 2016.

33. Parhiz H, Roohbakhsh A, Soltani F, Rezaee R and Iranshahi M: Antioxidant and anti-inflammatory properties of the citrus flavonoids hesperidin and hesperetin: An updated review of their molecular mechanisms and experimental models. Phytother Res 29: 323-331, 2015.

34. Yang L, Shi P, Zhao G, Xu J, Peng W, Zhang J, Zhang G, Wang X, Dong Z, Chen F, et al: Targeting cancer stem cell pathways for cancer therapy. Signal Transduct Target Ther 5: 8, 2020.

35. Bielecka ZF, Maliszewska-Olejniczak K, Safir IJ, Szczylik C and Czarnecka AM: Three-dimensional cell culture model utilization in cancer stem cell research. Biol Rev Camb Philos Soc 92: 1505-1520, 2017.

36. Liu XF, Yang WT, Xu R, Liu JT and Zheng PS: Cervical cancer cells with positive Sox 2 expression exhibit the properties of cancer stem cells. PLoS One 9: e87092, 2014.

37. Wang YD, Cai N, Wu XL, Cao HZ, Xie LL and Zheng PS: OCT4 promotes tumorigenesis and inhibits apoptosis of cervical cancer cells by miR-125b/BAK1 pathway. Cell Death Dis 4: e760, 2013.

38. Javed S, Sharma BK, Sood S, Sharma S, Bagga R, Bhattacharyya S, Rayat CS, Dhaliwal L and Srinivasan R: Significance of CD133 positive cells in four novel HPV-16 positive cervical cancer-derived cell lines and biopsies of invasive cervical cancer. BMC Cancer 18: 357,2018

39. Krebsbach PH and Villa-Diaz LG: The role of integrin $\alpha 6$ (CD49f) in stem cells: More than a conserved biomarker. Stem Cells Dev 26: 1090-1099, 2017.

40. Organista-Nava J, Gómez-Gómez Y, Garibay-Cerdenares OL, Leyva-Vázquez MA and Illades-Aguiar B: Cervical cancer stem cell-associated genes: Prognostic implications in cervical cancer. Oncol Lett 18: 7-14, 2019.

41. Tomita H, Tanaka K, Tanaka T and Hara A: Aldehyde dehydrogenase 1A1 in stem cells and cancer. Oncotarget 7: 11018-11032, 2016.

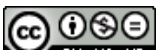

This work is licensed under a Creative Commons Attribution-NonCommercial-NoDerivatives 4.0 International (CC BY-NC-ND 4.0) License. 